\title{
Intestinal Fatty-Acid-Binding Protein in Neonatal Necrotizing Enterocolitis
}

Ehab A. Al-banna ${ }^{1}$, Hadeel M. Abd El-Rehman', Lamiaa M. M. Kamel' ${ }^{2}$, Ahmed E. M. Ahmed ${ }^{1 *}$

${ }^{1}$ Departments of Pediatrics \& ${ }^{2}$ Clinical Pathology, Faculty of Medicine, Zagazig University, Sharkia, Egypt

*Corresponding author: Ahmed El-Sayed Mohamed Ahmed, Mobile: (+20) 01094442192,

E-mail: elzawahry89@gmail.com

\begin{abstract}
Background: Necrotizing enterocolitis (NEC) is the most common gastrointestinal (GI) medical and surgical emergency occurring in neonates. It is an acute inflammatory disease with a multifactorial etiology; the condition is characterized by variable damage to the intestinal tract ranging from mucosal injury to fullthickness necrosis and perforation.

Objective: Our work aimed to detect the role of I-FABP in plasma in early diagnosis of NEC and prediction of severity of NEC among neonates at neonatal intensive care units, children's hospital, Zagazig University.

Patients and Methods: About 160 preterm neonates aging less than 35 weeks and weighing less than 2500 gm were included in this study to evaluate which of them will develop NEC, after follow up 24 of them developed NEC and still alive until the last samples were obtained from them. These neonates were diagnosed and classified according to Later Modified Bell's Staging for NEC.

Results: I-FABP level was highly increased in more complicated cases. We can predict NEC by the cut of value of IFABP $\geq 3.2 \mathrm{ng} \backslash \mathrm{ml}$ with sensitivity $95.8 \%$, specificity $95.8 \%$ at 1 st 24 hours, and at diagnosis by $\geq 9.2$ ng $\backslash \mathrm{ml}$ with sensitivity $95.8 \%$, specificity $100 \%$, and accuracy $0.99 \%$.

Conclusion: Serum IFABP can serve as a serological biomarker for early diagnosis of NEC for premature neonates with high accuracy and can predict the severity of the disease.
\end{abstract}

Keywords: Biomarker, Necrotizing Enterocolitis, Intestinal, Necrosis, Preterm Neonates and I-FABP.

\section{INTRODUCTION}

Necrotizing enterocolitis (NEC) is a common gastrointestinal disorder of newborns associated with high morbidity and mortality. It is also the leading cause of aberrant growth and neurodevelopment among surviving preterm infants ${ }^{(\mathbf{1})}$.

The best biomarkers should reflect the major steps in early disease pathogenesis. To detect NEC early in preterm with high risk, several biomarkers were investigated in the past decades, including markers of epithelial damage, smooth muscle injures, inflammation, and pathogen invasion. Fatty-acid-binding proteins (FABP) comprise a group of cytoplasmic small molecular mass proteins (14-15 kDa) with high organ sensitivity ${ }^{(2)}$.

Intestinal fatty acid-binding protein (i-FABP) constitutes up to $2 \%$ of the cytoplasmic protein content of the mature enterocyte. The plasmic contents, including i-FABP, are liberated into the circulation upon intestinal epithelial injury. IFABP can pass the glomerular filter with fractional renal excretion of $28 \%$ and a half-life of $1 \mathrm{~min}^{(3)}$.

As a consequence, plasma i-FABP levels may reflect the extent of intestinal epithelial cell damage. It is a noninvasive test to identify gut wall integrity loss and gut wall inflammation in infants with gastrointestinal symptoms suspected of NEC, Therefore, the plasma i- FABP (i-FABPp) is a promising biomarker in early diagnosis of NEC.
The plasma i-FABP increased in serum of patients with NEC and sepsis and even in otherwise healthy people after abdominal surgery, trauma, or alcohol consumption ${ }^{(4)}$.

\section{AIM OF THE WORK}

Our work aimed to detect the role of I-FABP in plasma in early diagnosis of NEC and prediction of severity of NEC among neonates at neonatal intensive care units, Children's hospital, Zagazig University.

\section{PATIENTS AND METHODS}

This study was a case-control study. It was conducted on preterm infants selected from the Neonatal Intensive Care Units (NICUs) of the Pediatric Department at Zagazig University hospital during the period from March 2018 until March 2019.

About 160 preterm neonates aging less than 35 weeks and weighing less than $2500 \mathrm{gm}$ were included in this study to evaluate which of them will develop NEC, after follow up for 10days 24 of them developed NEC and still present in our study until the last samples were obtained from them. These neonates were diagnosed and classified according to Later Modified Bell's Staging for NEC.

The 24 preterm neonates who developed NEC were defined as the case group. 
The other 24 preterm infants age and sex matching with the patient group but didn't develop NEC or sepsis or systemic inflammatory response syndrome were taken as a control group. These neonates were defined as the control group.

The remaining neonates, some of them died, others referred and excluded from our study.

The newborns included in the study were under the following inclusion and exclusion criteria:

Inclusion criteria: Preterm infant aged 35 weeks or less, both sexes and both inborn and outborn.

Exclusion criteria: Neonates with other GIT disease, Newborns with any congenital anomalies, Inborn error of metabolism, Fatal chromosomal defects, Full-term infants, and neonate doing major operation due to congenital anomalies or others GIT disease.

Ethical consideration: Approval of the study protocol by the Zagazig University Institutional Review Board (IRB) was obtained and informed consent was obtained from the parents before enrollment in the study.

Methods: The neonates incorporated in this study were subjected to the following: History. A full history of perinatal and obstetric history, hospitalacquired infections and necrotizing enterocolitis and daily resource utilization (entered daily); Full clinical examination including general examination and systemic examination

Investigation: Abdominal $x$-ray was done to both groups as well as laboratory investigations: Complete blood count (CBC), C-reactive protein (CRP), and Arterial blood gases (ABG).

Blood Sampling: Two milliliters of venous blood were withdrawn under aseptic precautions and were put in suited EDTA vacutainer (violet cap) and mixed up \& down gently. Mix for 10-20 mins .samples were centrifuged (at 2000 r.p.m for 20 minutes).Then remove supernatant the separated plasma used for assay I-FABP. And two-time points for the control group: Within $1^{\text {st }} 24$ hours of birth, the second samples after the start of feeding were taken at the time matching with the second samples of the case group (mainly around 6-10 postnatal days).

\section{Routine Laboratory Investigations:}

CBC was done for all samples using a fully automated cell counter (Sysmex 5, Xs 800). CRP: Qualitative C - reactive protein CRP: analyzed using latex agglutination. Results were considered positive above $6 \mathrm{mg} / \mathrm{l}$. Specific Laboratory Investigations: Serum intestinal fatty acid-binding protein (IFABP): was measured using human ELISA (sandwich technique) kits provided by SUN RED, China. (Catalog No. 201-12-1542).

\section{Statistical analysis:}

Data collected throughout history, basic clinical examination, laboratory investigations and outcome measures coded, entered, and analyzed using Microsoft Excel software. Data were then imported into Statistical Package for the Social Sciences (SPSS version 22.0) (Statistical Package for the Social Sciences) software for analysis. According to the type of data qualitative represent as number and percentage, a quantitative continuous group represented by mean $\pm \mathrm{SD}$, the following tests were used to test differences for significance; difference and association of qualitative variable by Chi-square test $\left(\mathrm{X}^{2}\right)$. Differences between parametric quantitative independent groups by t-test. P-value was set at < 0.05 for significant results $\&<0.001$ for high significant result.

\section{RESULTS}

Table (1): Comparison between cases and controls regarding demographic data.

\begin{tabular}{|c|c|c|c|c|c|c|}
\hline 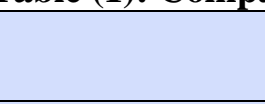 & 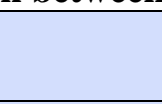 & & $\begin{array}{c}\text { Cases } \\
(\text { No. }=24)\end{array}$ & $\begin{array}{l}\text { Controls } \\
(\text { No. = 24) }\end{array}$ & t. test & P. value \\
\hline $\begin{array}{l}\text { Gestational age } \\
\text { (weeks) }\end{array}$ & \multicolumn{2}{|c|}{ Mean \pm SD } & $31.71 \pm 1.33$ & $32.88 \pm 1.51$ & 2.833 & 0.07 \\
\hline $\begin{array}{l}\text { Birth weight } \\
\text { (grams) }\end{array}$ & \multicolumn{2}{|c|}{ Mean \pm SD } & $1350 \pm 260$ & $1620 \pm 450$ & 2.501 & 0.06 \\
\hline \multirow{4}{*}{ Sex } & Males & No. & 14 & 11 & \multirow{4}{*}{$\begin{array}{c}\mathbf{X}^{\mathbf{2}} \\
0.083\end{array}$} & \multirow{4}{*}{0.773} \\
\hline & Males & $\%$ & $58.3 \%$ & $45.8 \%$ & & \\
\hline & \multirow{2}{*}{ Females } & No. & 10 & 13 & & \\
\hline & & $\%$ & $41.7 \%$ & $54.2 \%$ & & \\
\hline
\end{tabular}

There was no statistically significant difference between cases and controls regarding gestational age, birth weight, and sex among cases and controls. (Table 1) 
Table (2): Comparison between cases and controls regarding the plasma level of intestinal fatty acidbinding protein at 1st 24 hours, and at the time of diagnosis.

\begin{tabular}{|l|l|c|c|c|c|}
\hline \multicolumn{2}{|l|}{} & Cases (No.= 24) & Controls (No.= 24) & t.test & P. value \\
\hline $\begin{array}{l}\text { Plasma level of } \\
\text { intestinal fatty acid } \\
\text { binding protein at 1st } \\
\text { 24 hour (nglml) }\end{array}$ & Mean \pm SD & $6.99 \pm 1.959$ & $1.97 \pm 0.08$ & \multirow{2}{*}{7.987} & $0.0001 * * *$ \\
\cline { 2 - 5 } & Median & 6.43 & 2.11 & \\
\hline $\begin{array}{l}\text { Plasma level of intestinal } \\
\text { fatty acid-binding protein } \\
\text { at the time of diagnosis } \\
\text { (nglml) }\end{array}$ & Mean \pm SD & $20.98 \pm 4.339$ & $2.855 \pm 0.416$ & \multirow{2}{*}{10.498} & $0.0001 * * *$ \\
\cline { 2 - 5 } & Median & 19.47 & 2.69 & \\
\hline
\end{tabular}

$* * * \mathbf{P}$-value $\leq \mathbf{0 . 0 0 1}$

There was a statistically highly significant increase in plasma level of intestinal fatty acid-binding protein at 1st 24 hours and plasma level of intestinal fatty acid-binding protein at the time of diagnosis among cases than controls (Table 2).

Table (3): Comparison between plasma level of intestinal fatty acid-binding protein at 1 st 24 hours, and at the time of diagnosis between cases.

\begin{tabular}{|l|c|c|c|c|}
\hline & $\begin{array}{c}\text { Plasma level of intestinal fatty } \\
\text { acid-binding protein at 1st 24 } \\
\text { hours (nglml) }\end{array}$ & $\begin{array}{c}\text { Plasma level of intestinal } \\
\text { fatty acid-binding protein } \\
\text { at the time of diagnosis } \\
(\mathrm{ng} \backslash \mathrm{ml})\end{array}$ & t-test & P-value \\
\hline Mean \pm SD & $6.99 \pm 1.959$ & $20.98 \pm 3.339$ & 20.42 & $0.0001 * * *$ \\
\hline Median & 6.43 & 19.47 & 20.47 \\
\hline
\end{tabular}

$* * * P$-value $\leq \mathbf{0 . 0 0 1}$

There was a statistically highly significant increase in plasma level of intestinal fatty acid-binding protein at the time of diagnosis than at 1 st 24 hours. (Table 3 )

Table (4): Comparison between patients with positive and negative CRP regarding plasma level of intestinal fatty acid-binding protein at 1st 24 hours and plasma level of intestinal fatty acid-binding protein at the time of diagnosis.

\begin{tabular}{|l|c|c|c|c|c|}
\hline \multicolumn{2}{|l|}{} & $\begin{array}{c}\text { Positive CRP) } \\
\text { No.= 20) }\end{array}$ & $\begin{array}{c}\text { Negative CRP) } \\
\text { No.= 4) }\end{array}$ & t.test & P. value \\
\hline $\begin{array}{l}\text { Plasma level of } \\
\text { intestinal fatty acid- } \\
\text { binding protein at } \\
1 \text { st 24 hours } \\
\text { (ng\ml) }\end{array}$ & Mean \pm SD & $7.7318 \pm 1.65$ & $3.286 \pm 0.8336$ & 3.269 & $0.004 * *$ \\
\hline $\begin{array}{l}\text { Plasma level of } \\
\text { intestinal fatty acid- } \\
\text { binding protein at } \\
\text { the time of } \\
\text { diagnosis (nglml) }\end{array}$ & Mean \pm SD & $\begin{array}{c}23.126 \pm \\
3.324\end{array}$ & $10.26 \pm 2.085$ & 3.404 & $0.003^{* *}$ \\
\hline
\end{tabular}

**P-value $\leq \mathbf{0 . 0 1}$

There was a statistically significant increase in plasma level of intestinal fatty acid-binding protein at 1 st 24 hours and at the time of the diagnosis among infants with positive than with negative CRP. (Table 4) 


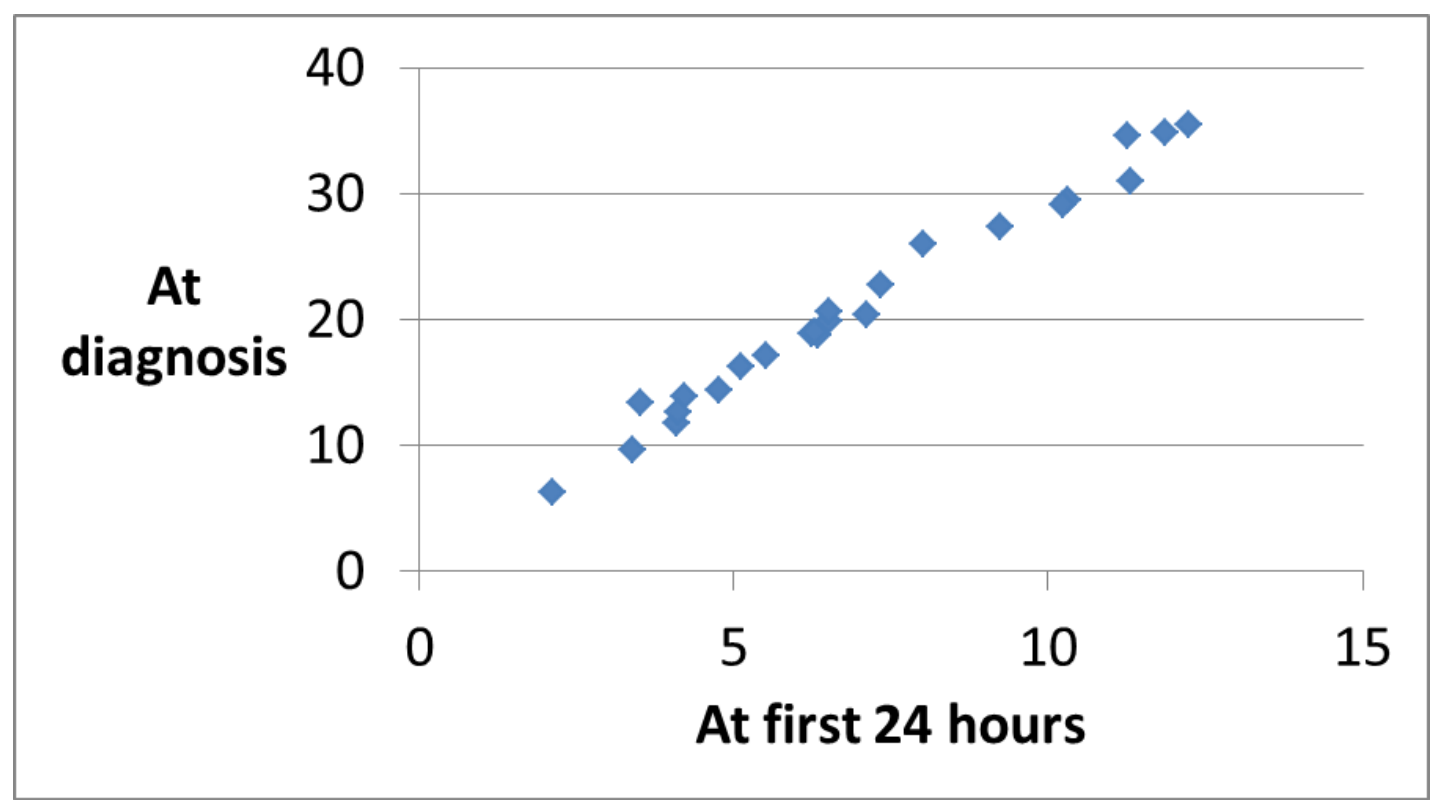

Figure (1): Correlation between plasma level of intestinal fatty acid-binding protein at the time of diagnosis and plasma level of intestinal fatty acid-binding protein at 1 st 24 hours.

There was a statistically significant positive correlation between the plasma level of intestinal fatty acidbinding protein at the time of the diagnosis and 1st 24 hours. (Figure 1)

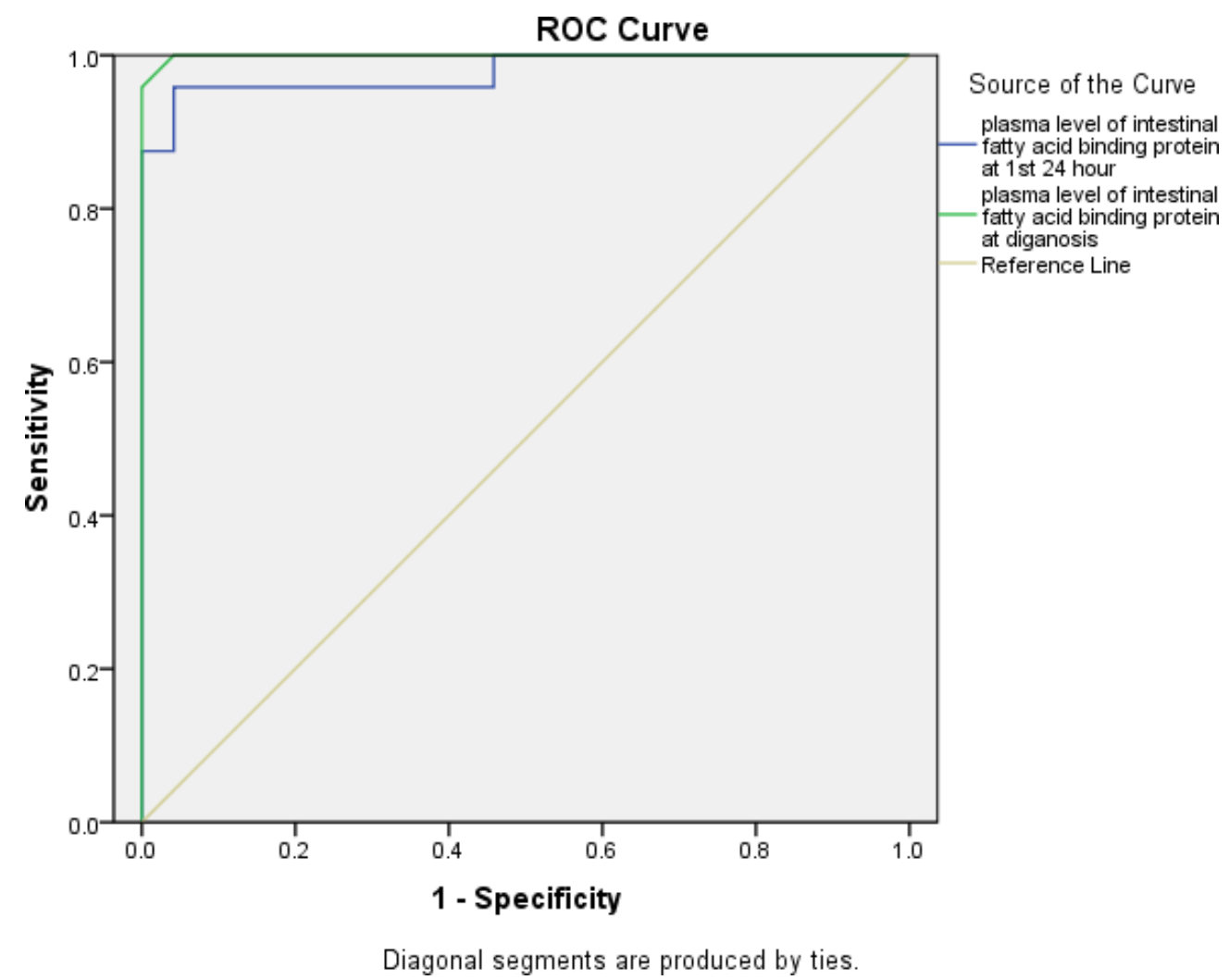

Figure (2): ROC curve, sensitivity, specificity, PPV, NPV, and accuracy of the plasma level of intestinal fatty acid-binding protein at 1st 24 hours as well as the plasma level of the intestinal fatty acid-binding protein at the time of the diagnosis of NEC.

Cut off value of the intestinal fatty acid-binding protein at 1 st 24 hours was $\geq 3.2 \mathrm{ng} \backslash \mathrm{ml}$ with sensitivity $95.8 \%$, specificity $95.8 \%$, and accuracy 0.97 , and that cut off value of intestinal fatty acid-binding protein at the time of the diagnosis was $\geq 9.2 \mathrm{ng} \mathrm{lml}$ with sensitivity $95.8 \%$, specificity $100 \%$, and accuracy $0.99 \%$. (Figure 2 ) 


\section{DISCUSSION}

Because NEC is characterized by loss of bowel wall integrity, intestinal fatty acid-binding protein I-FABPis one of the more promising biomarkers. This small cytosolic protein, located mainly in enterocytes of the small intestine, is released into the bloodstream after cell disruption (5).

Intestinal fatty acid-binding protein (IFABP), which is released into the circulation from damaged enterocytes and is excreted in the urine. It has been shown in many studies that I-FABP is increased around the time of development of $\mathrm{NEC}^{(1)}$.

The present study showed a highly significant increase in plasma level of intestinal fatty acid-binding protein at $1^{\text {st }} 24$ hours in the case group $(6.99 \pm 2.959)$ than in the control group (1.97 $\pm 0.84)$. This coped that study conducted by AbdelHaie et al. ${ }^{(6)}$ who reported that regarding plasma IFABP values; comparing between the case group and control as regarding plasma level of intestinal fatty acid-binding protein at 1 st 24 hours in case group was $11.76 \pm 4.09$ and in the control group was $(3.12 \pm 1.4)$ show a highly significant statistical increase in its level in the patient group. I-FABP levels plotted against time is the peak early-on in the course of the disease, i.e. within 24 hours after symptom onset. A possible explanation for this course in I-FABP levels starts with the fact that IFABP is expressed in mature enterocytes (rather than in the crypts) and that these cells are located at the most distal point from the mucosal blood supply ${ }^{(7)}$.

Regarding serum IFABP values; the $1^{\text {st }}$ values of IFABP taken within $1^{\text {st }} 24$ hours of birth showed that the mean serum IFABP concentrations of the case group were higher than that of the control group. This was in agreement with a previous study by Schurink $\boldsymbol{e t}$ al. ${ }^{\left({ }^{(8)}\right.}$ who reported that mean serum IFABP concentration at birth was $8.6(\mathrm{ng} / \mathrm{ml})$ in NEC cases. This indicates that the IFABP level at $1^{\text {st }} 24$ hours can predicate the occurrence of NEC and can help in the early diagnosis of NEC.

The $2^{\text {nd }}$ values of taken at age of diagnosis mainly around (2-10 postnatal days) showed that the mean IFABP concentrations of the study group were $20.98 \pm 9.33(\mathrm{ng} / \mathrm{mL})$ which is significant in comparison with IFABP at birth. This indicates that the level of IFABP can confirm the diagnosis of NEC.

The present study showed that significant increase in plasma level of IFABP at 1st 24 hours and plasma level of IFABP at diagnosis among cases than controls and statistically significant difference between each stage with other except between stage $1 \mathrm{~A}, 1 \mathrm{~B}$ and stage $2 \mathrm{~A}$ and $2 \mathrm{~B}$ regarding Plasma level of IFABP at 1st 24 hours there was a statistically significant difference between each stage and other except between stage $2 \mathrm{~A}$ and $2 \mathrm{~B}$ regarding plasma level of IFABP at diagnosis so there was an increase in IFABP level in more complicated cases so it can be used to detect the severity of NEC ${ }^{(9)}$.

Our results demonstrated that I-FABP had diagnostic and prognostic properties. This was in agreement with the previous study by $\mathbf{N g}$ et al. ${ }^{(10)}$, who showed that I-FABP is a potentially useful biomarker for differentiating between NEC and control patients with suspected clinical sepsis or NEC. Similar to our results, they found significantly higher I-FABP levels in NEC infants than in the control group. Recently, in a study comparing I-FABP with other potential markers, Benkoe et al. (2) reported that I-FABP concentrations were significantly higher in NEC infants compared with controls.

Early and reliable diagnosis of NEC is important to offer opportunities for early intervention, our results succeeded in early diagnosis and prediction of NEC. This was in agreement with a previous study by Gregory $\boldsymbol{e t} \boldsymbol{a l}$. (11) who illustrated that within 7 days before NEC, iFABP > $13.3(\mathrm{ng} / \mathrm{mL})$ would predict NEC with $60 \%$ sensitivity and $78 \%$ specificity.

In contrast to our study, Thuijls et al. ${ }^{(12)}$ found that I-FABP levels were not elevated before clinical suspicion of NEC. Their results found that I-FABP levels were only elevated at the moment of suspicion and screening for NEC with the current tool seemed not to be useful.

Also, several earlier studies reported that IFABP measured in plasma and serum might serve as a diagnostic marker for early intestinal mucosal compromise, such as NEC ${ }^{(7)}$.

Thuijls et al. ${ }^{(12)}$ concluded, based on single samples, that I-FABP could improve early diagnosis of intestinal ischemia. In the same year, a study on I-FABP measured in serum instead of plasma,

Schurink et al. ${ }^{(8)}$ demonstrated that as early as the first eight hours after the onset of nonspecific gastrointestinal symptoms, I-FABP had valuable diagnostic and prognostic properties.

Abdel-Haie $\boldsymbol{e t}$ al. ${ }^{\left({ }^{6}\right)}$ reported that the 1st values of IFABP taken at birth showed that mean serum IFABP concentrations of the study group were higher than that of the control group. And IFABP taken at the time of diagnosing NEC showed that mean serum IFABP concentrations of the study group were higher than the control group. 
In our study, CRP was positive in $83 \%$ of cases of case group there was a significant increase in plasma level of intestinal fatty acid-binding protein at 1 st 24 hours and at diagnosis among positive than negative CRP.

The present study shows that the cut off value of IFABP at $1 \mathrm{st} 24$ hours was $\geq 3.2 \mathrm{ng} \backslash \mathrm{ml}$ with sensitivity $95.8 \%$, specificity $95.8 \%$, and accuracy 0.97 , and that cut off value of IFABP at diagnosis $\geq 9.2 \mathrm{ng} \backslash \mathrm{ml}$ with sensitivity $95.8 \%$, specificity $100 \%$, and accuracy $0.99 \%$. Cut-off values for I-FABP determined in our study correspond to a high specificity to minimize the chance of erroneously establishing the diagnosis of NEC. By performing serial I-FABP measurements the chance of false-negative results will be further minimized.

Terrin et al. ${ }^{(13)}$ reported that intestinal fatty acid-binding protein with senitivity $100 \%$ and specificity $91 \%$ when tested to predict the evolution from definite to advanced NEC.

However, Abdel-Haie et al. ${ }^{(6)}$ reported that area under curve (AUC) value was $0.99,95 \%$ Cutoff point of I-FABP for prediction of NEC is estimated to be $\geq 7.75 \mathrm{ng} / \mathrm{ml}$ at birth with sensitivity $94.4 \%$ and specificity of $100 \%$. While at the cutoff point of I-FABP for prediction of NEC is estimated to be $\geq 37.95 \mathrm{ng} / \mathrm{ml}$ at diagnosis with sensitivity $100 \%$ and specificity of $100 \%$.

\section{CONCLUSION AND RECOMMENDATIONS}

Serum IFABP can serve as a serological biomarker for early diagnosis of NEC for premature neonates with high accuracy and can predict the severity of the disease.

\section{REFERENCES}

1. Eaton S, Rees CM, Hall NJ et al. (2017): Current Research on the Epidemiology, Pathogenesis, and Management of Necrotizing Enterocolitis. Neonatology, 111(4): 423-430.

2. Benkoe TM, Mechtler TP, Weninger M et al. (2014): Serum levels of interleukin-8 and gutassociated biomarkers in diagnosing necrotizing enterocolitis in preterm infants. J Pediatr Surg., 49:1446-1451.

3. Van de Poll MC, Derikx JP, Buurman WA et al. (2007): Liver manipulation causes hepatocyte injury and precedes systemic inflammation in patients undergoing liver resection. World .J Surg., 31:20338.

4. Bingold TM, Franck K, Holzer K et al. (2015): intestinal fatty acid-binding protein: a sensitive marker in abdominal surgery and abdominal infection. Surgical Infections, 16(3): 247-253.

5. Relja B, Szermutzky M, Henrich D et al. (2010): Intestinal-FABP and liver-FABP: Novel markers for severe abdominal injury. AcadEmerg Med., 17(7):729-35.

6. Abdel-Haie OM, Behiry EG, Almonaem ER et al. (2017): Predictive and diagnostic value of serum intestinal fatty acid-binding protein in neonatal necrotizing enterocolitis (case series). Annals of Medicine and Surgery, 21: 9-13.

7. Lieberman JM, Sacchettini J, Marks C et al. (1997): Human intestinal fatty acid-binding protein: Report of an assay with studies in normal volunteers and intestinal ischemia. Surgery, 121(3):335-42.

8. Schurink M, Scholten IGH, Kooi EMW et al. (2015): Intestinal fatty acid-binding protein in neonates with imminent necrotizing enterocolitis. Neonatology, 106(1):49-54.

9. Aydemir C, Dilli D, Oguz SS et al. (2011): Serum intestinal fatty acid-binding protein level for prediction of severity of necrotizing enterocolitis. Early Hum Dev., 87: 659-661.

10. Ng EW, Poon TC, Lam HS et al. (2013): Gutassociated biomarkers L-FABP, I-FABP, and TFF3 and LIT score for the diagnosis of surgical necrotizing enterocolitis in preterm infants. Ann Surg., 258: 11-8.

11. Gregory KE, Winston AB, Yamamoto HS et al. (2014): Urinary intestinal fatty acid-binding protein predicts necrotizing enterocolitis. The Journal of Pediatrics, 164(6): 1486-1488.

12. Thuijls G, van Wijck K, Grootjans J et al. (2011): Early diagnosis of intestinal ischemia using urinary and plasma fatty acid-binding proteins. Ann Surg., 253:303-8.

13. Terrin G, Stronati L, Cucchiara S et al. (2017): Serum markers of necrotizing enterocolitis: a systematic review. Journal of Pediatric Gastroenterology and Nutrition, 65(6): 120-132. 